\title{
Knowledge-Salvage Practices for Dormant R\&D Projects
}

Oya I. Tukel

Cleveland State University, o.icmeli@csuohio.edu

Tibor Kremic

Walter O. Rom

Cleveland State University, w.rom@csuohio.edu

Richard J. Miller

Cleveland State University

Follow this and additional works at: https://engagedscholarship.csuohio.edu/bus_facpub

Part of the Business Administration, Management, and Operations Commons

How does access to this work benefit you? Let us know!

\section{Publisher's Statement}

This is the accepted version of the following article: Tukel, O. I., Kremic, T., Rom, W. O., Miller, R.

J. (2011). Knowledge-Salvage Practices for Dormant R\&D Projects. Project Management Journal, 42 (1), pp. 59-72., which has been published in final form at 10.1002/pmj.20207

\section{Original Published Citation}

Tukel, O. I., Kremic, T., Rom, W. O., Miller, R. J. (2011). Knowledge-Salvage Practices for Dormant R\&D Projects. Project Management Journal, 42 (1), pp. 59-72.

This Article is brought to you for free and open access by the Monte Ahuja College of Business at EngagedScholarship@CSU. It has been accepted for inclusion in Business Faculty Publications by an authorized administrator of EngagedScholarship@CSU. For more information, please contact library.es@csuohio.edu. 


\section{Knowledge-Salvage Practices for Dormant R\&D Projects}

Oya I. Tukel, Cleveland State University, Cleveland, OH, USA

Tibor Kremic, NASA John H. Glenn Research Center, Cleveland, OH, USA

Walter O. Rom, Cleveland State University, Cleveland, OH, USA

Richard J. Miller, Cleveland State University, Cleveland, OH, USA

\section{ABSTRACT}

Most successful firms have an abundance of new and old knowledge in their research and development laboratories, and only a fraction is being put into use in new product development. This knowledge is left over from projects that have been killed at different development stages and may actually carry considerable value. In this article, we propose a knowledge bank as a possible solution to preserve and possibly grow this knowledge. It is a selfsustaining institute with minimal or no ongoing effort from the donor company, yet manages the knowledge in a way that protects proprietary interests and actively fosters communication and interchange among sponsoring companies wherever possible. The framework of this structure, as well as how it works, is described here. Specifically, a system dynamics modeling of the knowledge bank is developed, and a simulation study is conducted using VENSIM ${ }^{\circledR}$. The results confirm the viability of creating such a system in a consortium of organizations.

KEYWORDS: R\&D projects; knowledge banks; system dynamics

\section{INTRODUCTION}

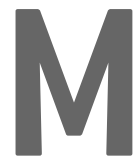

any examples of dormant or abandoned projects can be found in the research and development (R\&D) laboratories of incumbent corporations. These corporations are in a race of developing and launching a steady stream of new products hoping to satisfy their loyal customers and attract new customers in potential new markets. An idea-to-launch process such as a stage-gate process guides the product managers in terms of deciding which product-development projects have merit to be investigated further and which ones to kill (Cooper, 1985). The process consists of stages and gates. At the stages, a set of activities is performed to develop the product concept further, and the gates are structured as decision points where the gatekeeper, typically the sponsor or product manager, evaluates the performance of the project to date and makes a go/kill decision. This evaluation can be done on the basis of a ranking recommended by Linton and Walsh (2004), or on the basis of R\&D performance indices developed by Osawa and Yamasaki (2005). Many product-development projects are typically terminated at different gates throughout the process, and resources are reallocated to more promising projects. After starting with numerous product concepts, only a few survive to reach the later development stages, and only one may be introduced to the markets.

But what happens to the abandoned or "killed" projects at these various gates? Depending upon when they are terminated, they might carry considerable value. Many companies, however, consider these efforts as sunk or stranded costs and walk away, although years later there could be renewed interest, resulting in an effort to resume them. This article addresses the deficiencies in current corporate R\&D practices to salvage these projects, and offers a possible solution to knowledge loss in the form of what we call a knowledge bank.

\section{Dormant Projects}

Dormant projects are defined as those projects that have extended breaks due to events such as funding lapses, market readiness, temporary loss of interest, external factors such as wars, or perhaps availability of supporting or ancillary technologies (Tukel, Rom, \& Kremic, 2007).

These projects do not go through typical project life cycles, and at the time of termination, there is usually no clear indication of when or if they will ever be restarted. In a stage-gate context, the company's interest is to limit any additional investment in these projects. Thus, very limited, if any, use is made of knowledge management and retention tools, such as close-out documents. The accumulated loss of knowledge is substantial since, over the years, the vast majority of new product-development projects initiated will not be completed. Although some corporations seek patents for some of the 


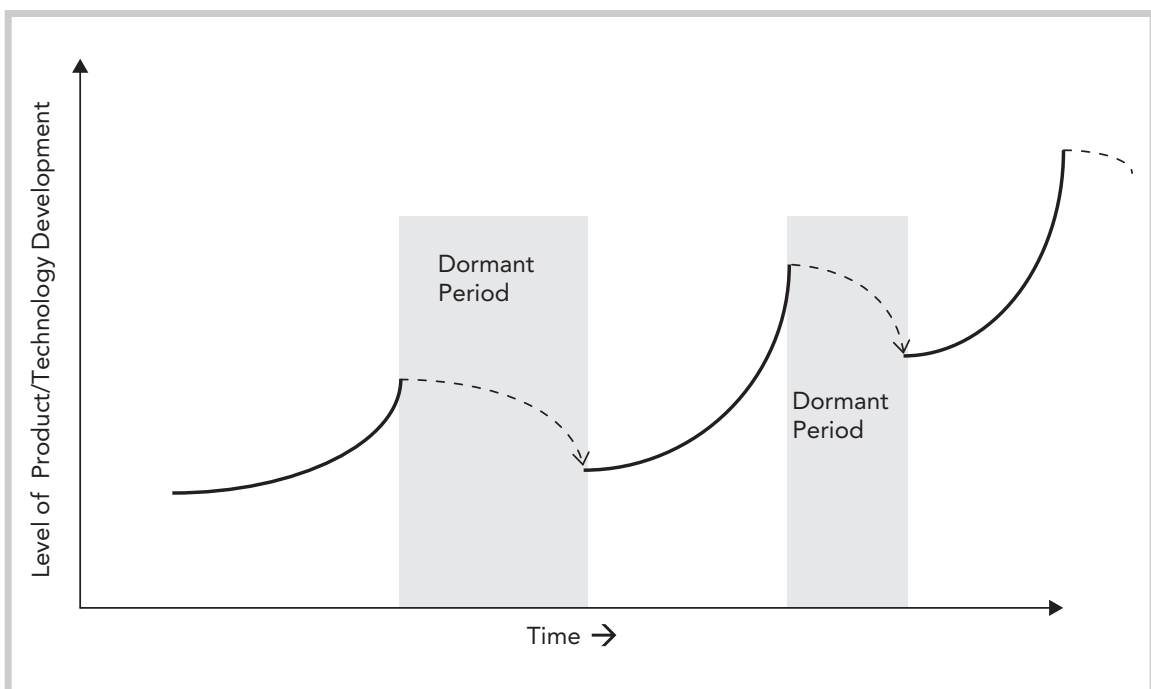

Figure 1: Product/technology development life cycle.

efforts put into the development as a way to recoup some of the value of their investment, early terminations might prevent this (Elmquist \& Masson, 2009).

The product/technology development effort for dormant projects is shown in Figure 1. This figure depicts the well-known $S$-curve theory showing the pattern of project progress. Both the empirical and theoretical research that has appeared in the literature in the last 30 years show that most new productdevelopment efforts follow an S-curvethat is, slow-rapid-slow progress (see, for example, Foster, 1986; Henderson, 1988; Sahal, 1981). The $y$-axis specifies the magnitude of improvement in the development of a product for a given period of time in the project timeline. At the early stages, the rate of progress is relatively slow since much of the technological knowledge is unknown. There is an exponential growth of product/technology realization when the project is in full swing (Christensen, 1992). At this stage, quick response-to-market needs motivate companies to allocate more resources to the project. However, when the project terminates immaturely (dormant period), the level of effort drops sharply and project development comes to a halt. The length of time between the executions of successive starts impacts the quality and relevance of the transferred knowledge. When the time between the termination of a project and the restart of it is short, the project environment can be quite similar and thus result in a maximum usage of existing knowledge. On the other hand, when there are long lapses between project implementations, then changes in the project environment, which include human resources and technology, lead to loss of relevance of the accumulated knowledge and thus causes the restart at a lower level of development, indicating that some level of rework is needed.

\section{Issues When Reinstating Projects}

Many of the individuals with tacit knowledge who participated in the early development stages of dormant projects will have either lost the knowledge due to time lapses or are no longer a part of the project. In other words, the organization will not have the tacit knowledge when the product-development project is revived, as tacit knowledge remains with the people involved (Koskinen, 2002).

There would also be significant challenges with retrieving the explicit knowledge. Documents would have been discarded, lost, or inaccessible to those seeking the knowledge. Documents may become damaged or destroyed in storage, depending on the length of time since they were deposited. Perhaps the indexes or search tools designed to help users find information in the documents are lost or of such a nature that the documents become useless. Perhaps it may take longer to find the knowledge than to re-create it. Storage media is also a consideration. Information that is stored in electronic format runs the risk that by the time the information is needed, the equipment, software, or know-how to recover it won't exist. Along with the media, the formats change. Databases come and go with the spreadsheets and other software that are required to process the data. So along with having the right equipment, the appropriate versions of the software may also be required.

Another significant challenge exists in determining what type of information/ data will be needed later. Due to the uncertainty of $R \& D$ success and failures, predicting how and where knowledge will be used is difficult. Technology revolutions may radically change what may currently seem valuable. For example, the growth of digital technology has had a tremendous impact on various media and entertainment industries, resulting in the obsolescence of much of the knowledge accumulated over a century, such as optical film. Revolutionary leaps in technology, however, do not occur that often. Thorough forethought and deliberate knowledge management would be expected to offer considerable benefit on project restarts.

Finally, it may be reasonable to assume that organizations are efficient and will not maintain a functional organizational structure to support work that no longer exists. The possibility of renewed activity years in the future may not result in a decision to bridge that long gap. The implication, of course, is that there will be no internal group to nurture the skills and knowledge.

The following are two examples of dormant projects. Although they were implemented in relatively different 
industries, they both have similar characteristics, and their technology development efforts both follow the one we suggested in Figure 1.

\section{Development of Electrical Vehicle Technology}

A good example that illustrates the occurrence of interruptions in the development of a product is electric vehicles. The first electric car was built by 1839 , and, by the 1900 s, American car companies (including the Electric Vehicle Company) were making electric vehicles. By this date, 1,575 electric cars had been produced. It appeared that electric cars were to be the transportation of choice for the future. Considerable research and development efforts by corporations as well as entrepreneurs continued to improve electric-car technology until the challenges posed by gasoline-powered cars were overcome. The assembly-line production of low-priced, lightweight, gas-powered vehicles disrupted the electric car markets to the extent that, by 1913, electric cars and the technology investment in electric vehicles were almost completely wiped out. Electric vehicles totally disappeared from U.S. markets by 1935 .

The years between 1935 and the 1960s were dormant years for electric vehicle development projects. In the 1960s and 1970s, there was a growing need for alternative vehicles to reduce the problems of exhaust emissions from internal combustion engines and to reduce the dependency on imported foreign crude oil. This need in the economy restored the investment into electric-car technology. Many new attempts to produce practical electric vehicles occurred during the years from 1960 to the present. During that 30-year period, not only electric vehicle production but also the knowledge created to produce electric cars went dormant. Since no one company or individual was the sole owner of the technology, no one company or individual retained and improved upon the knowledge (Motavalli, 2001).

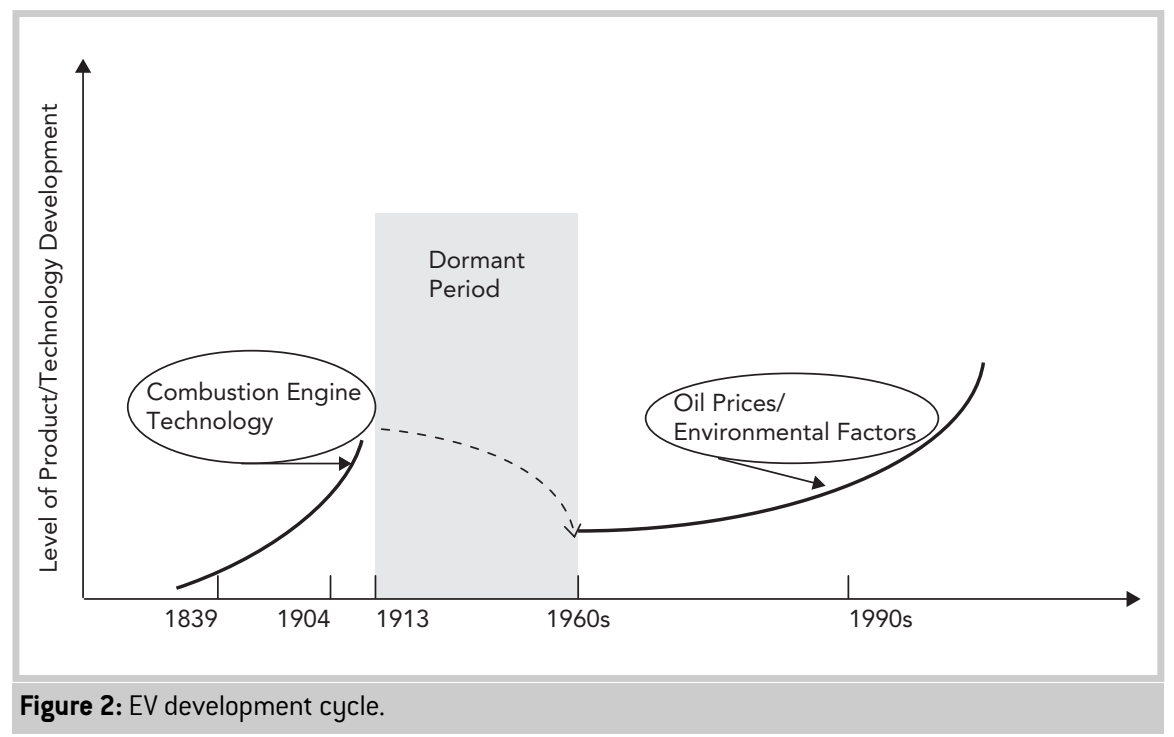

It is only since after the 1990s that the big three automobile companies in the United States started producing electric vehicles for mass markets. General Motors developed the EV1 for the California market, although it was subsequently withdrawn. Typically, these organizations retained limited explicit knowledge and none of their tacit knowledge from the 1920s and 1960s when the electrical vehicle development projects were revived.

The product-development effort is depicted in Figure 2. The long dormant period from the early 1910s to the 1960s is the main reason for this technology to almost start from scratch. Obviously, many knowledge management (KM) tools such as repositories and portals were not in existence, and most development efforts were kept in written documents that were lost as car companies vanished. Another issue that may have contributed to the lost knowledge was that although the kernel knowledge on electrical vehicles was applicable, by the 1960s electric car manufacturing processes and technology were not. A further challenge was that technology in combustion engine-driven automobiles had continued to improve. This resulted in longer-than-expected development times in electric vehicle technology, higher development costs, and thus high sales prices, slower speeds, and shorter trip ranges. In general, this resulted in poorer performance of electric vehicles compared with what users of the day expected from their cars.

\section{Development of Nuclear Technology at NASA}

The National Aeronautics and Space Administration's (NASA's) investment in nuclear technology began in the late 1950s with the initiation of the Rover and the Nuclear Energy for Rocket Vehicle Application (NERVA) programs. These projects were implemented in cooperation with the Atomic Energy Commission. The Rover project was a technology development effort conceived to develop small nuclearpowered rocket engines as possible backups for chemically powered rockets. Its sister project, NERVA, was formulated to achieve both ground and flight demonstration of nuclear thermal-powered rocket engines (Bowles \& Arrighi, 2004).

For approximately 25 years, NASA continued to study and build knowledge on nuclear-based propulsion and power. Materials were characterized in the radiation environment. Propellant formulation experiments were conducted. Engine designs were assessed and tested. During this process, numerous 
reports were written, processes and procedures were developed, hardware was fabricated, and personnel were trained. By 1973, knowledge on this subject had come a long way. In fact, 20 nuclear thermal propulsion rocket engines had been built and tested. These ranged from relatively small 25$\mathrm{kW}$ engines up to $250-\mathrm{kW}$ devices. The technology was so promising that it was planned as a backup approach to power lunar spacecraft in the event that the primary chemical-propulsion options failed to meet mission requirements.

By the early 1970s, the environment for NASA changed dramatically. The Apollo program, once a well-funded effort clearly in the public eye, began to lose public interest. Missions to the moon, the ability to get there, and the retrieval of specimens ceased to have relevance for many. The high cost of the NASA programs, the resource needs in other areas, and the lack of public interest all combined to cause the U.S. Congress to abruptly end the Apollo program. Without the Apollo program and NASA funds shifting to the development of the space shuttle, there was no obvious near-term demand for nuclear power or propulsion; thus, NERVA and Rover were terminated.

The project remained dormant for approximately 15 years until the start of the space exploration initiative. Nuclear technology was explored for powering $100-\mathrm{kW}$ nuclear electric propulsion thrusters under the so-called SNAP (Systems for Nuclear Auxiliary Power) program (Bennett, Hemler, \& Schrock, 1996). This investment abruptly ended in 1993 shortly after the change in presidential administrations. Investment in nuclear technology lay dormant again, this time for about a decade.

The restart of nuclear technology development in 2003 was also a result of political changes. This program included both technology development as well as a robotic science mission to the icy moons of Jupiter, called the JIMO mission. Nuclear technology was essential to accomplish this mission, and nuclear technology development was an important aspect of the efforts under this program. For a variety of reasons, NASA chose to partner with Naval Reactors (NR), which is associated with both the Navy and the U.S. Department of Energy. NR is a research organization that specializes in reactor designs and was given roles in the design of nuclear portions of the JIMO mission. The renewed interest by NASA was to be short-lived. Events with the space shuttle, demands of the International Space Station, and the new vision for space exploration that was announced in 2004 placed increasing demand on the NASA budget to the point that the U.S. \$10-to-15-billion JIMO mission was cancelled as well as the nuclear work started at NR. As of 2006, only a few million dollars is budgeted for nuclear technology work and is simply an attempt at sustaining some level of nuclear capability within NASA. The progress of nuclear technology development at NASA is presented in Figure 3.

\section{Content of Knowledge Banks}

A firm can be made up of a variety of differing resources that allow it to compete within the market (Barney, 1991; Wernerfelt, 1984). Resources (that is, machinery, capital, etc.) can be either used immediately or stored to provide a future benefit to a firm. A firm's resources can be represented by the knowledge used to produce new products and processes (Grant, 1996; Spender, 1996). Knowledge resources can also be used immediately or stored to provide a future benefit to a firm. The proposed knowledge bank is an accumulation of these knowledge resources that do not possess a current benefit to the firm but may be of future value.

Knowledge contained within a firm's current and dormant projects represents a stock of stored knowledge. Moorman and Miner (1997) refer to this stock of knowledge as organizational memory. For organizational memory to be useful, it should be in a storable and retrievable format (Huber, 1991). When organizational memory stocks are retrieved, they have two positive aspects to a firm in its development of products. The first benefit is the ability to remember what has worked in the past, and the second benefit is the ability to remember what did not work (Day, 1991). Both of these qualities of the knowledge bank can allow firms to access the successes and failures of previous projects so that what went right and what went wrong can be retained and remembered at a future time.

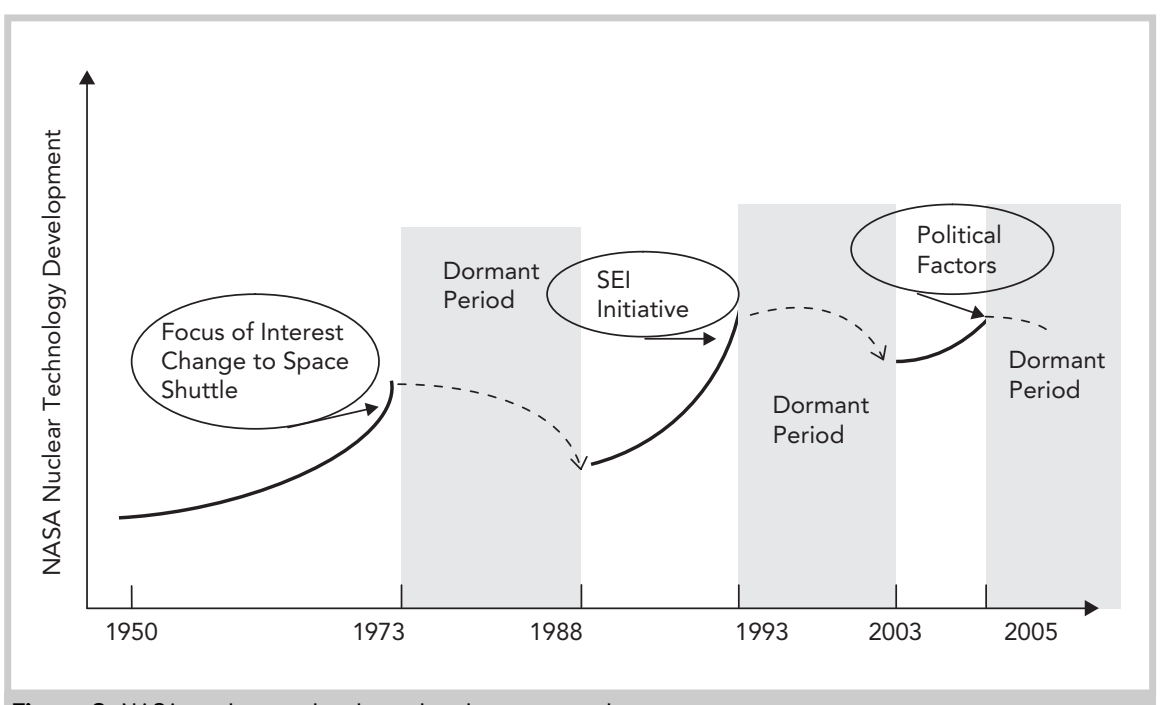

Figure 3: NASA nuclear technology development cycle. 


\section{Creation of Knowledge Banks}

It is clear in the previous examples that the reasons a project goes dormantnamely, lack of funds, lack of current interest, or external environmental factors-imply that minimal resources, desire, and effort will be available internally to retain the knowledge and technology developed. Given this situation, a feasible method that can be employed by a corporation for salvaging knowledge requires minimal or no ongoing effort, inherent staying power, and management of knowledge in a way that protects proprietary interests yet actively fosters communication and interchange whenever possible.

Staying power in this context refers to the ability of the solution process to sustain its own existence for long periods of time relatively independent of external events. Because dormant projects will likely be in a dormant state for a long and unknown period of time, one cannot easily estimate how much resources or time will be required to bridge the dormancy gap. Therefore, knowledge-management solutions will need to be unique and independent of the project-and possibly even the organization that sponsored the project.

Managing knowledge such that proprietary interests are protected yet open information is actively shared is key to long-term knowledge management for dormant projects. Once again, it must be assumed that the organizational resources and structure that support the project cease to exist during the dormant period. Assuming also that valuable and possibly proprietary knowledge exists under the project, one must find a place to store that knowledge or, better yet, a place to grow that knowledge even during dormancy. The need to foster and grow the knowledge outside of the organizational boundaries is a common situation faced by most organizations, which might motivate them to form consortia or alliances (West \& Gallagher, 2006).
If a project or organization has knowledge that is not needed in the immediate future, it should be stored with an entity that specializes in managing knowledge-that is, an institute. Ideally, the knowledge will be managed such that more comes out than was initially put in. The term knowledge bank (KB) describes an institute that performs this function. Figure 4 shows the proposed structure. It is a dynamic system that consists of several elements. The resources needed for the KB to foster and grow the knowledge are human resources such as researchers, scientists, librarians, students, or faculty; knowledge resources such as documents, manuals, databases, or licenses; and physical resources such as computer hardware and software, equipment, and buildings. The $\mathrm{KB}$ requires funding initially from sponsoring companies, although with time, the value created would enable the bank to sustain itself. Similar collaborative structures have appeared in high-innovation growth

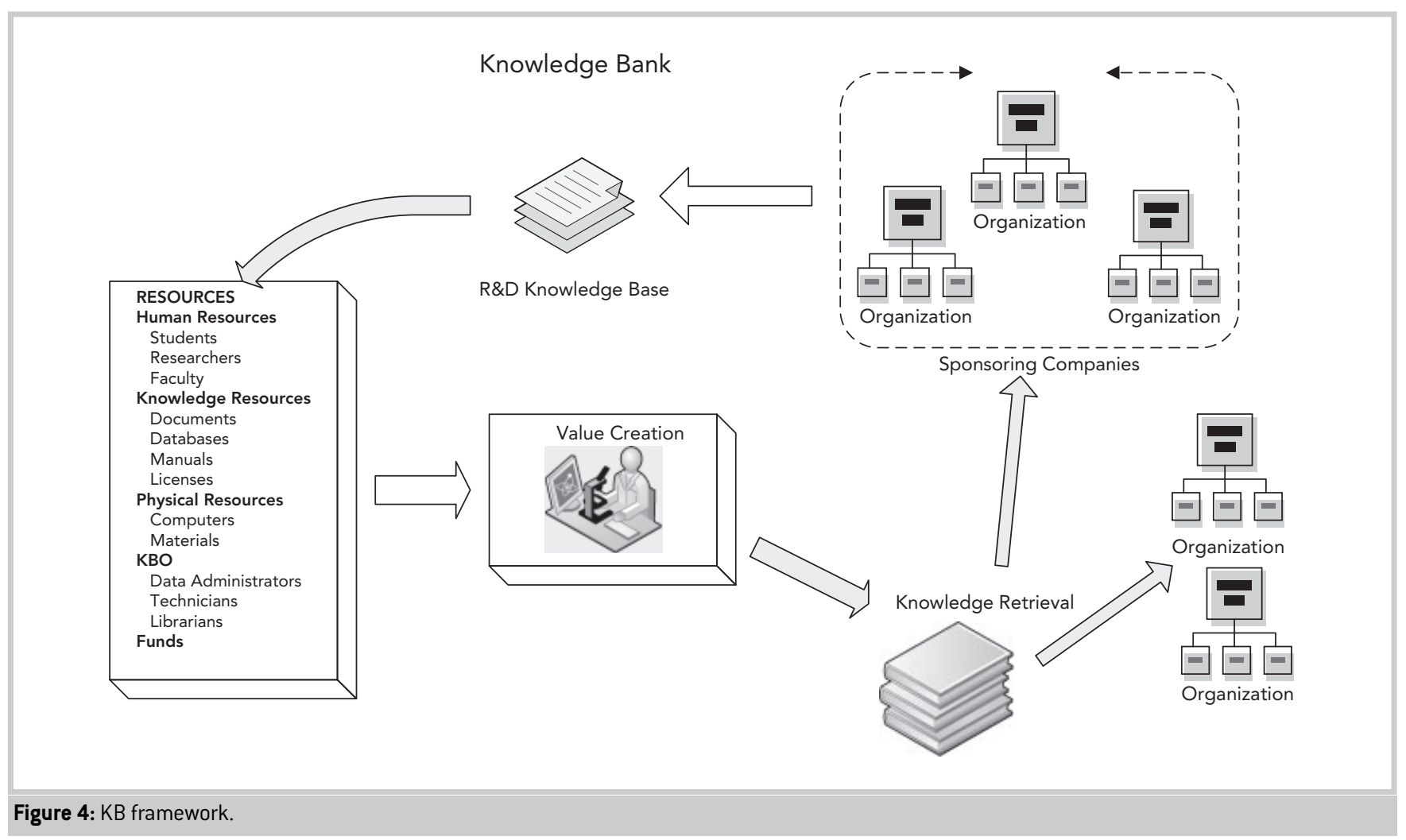


areas such as nanotechnology, media laboratories, and computing (Chesbrough \& Crowther, 2006). MIT established a media laboratory around 1985, with the intention of creating a structure that allows researchers to pursue radical and risky projects that would otherwise not be funded in a typical corporate environment (Brand, 1988). Similarly, the Albany Nanotech Center provides a common place for creating alliances among companies like IBM and Sony to support their R\&D work (www.albanynanotech.org). They suggest an open innovative strategy where knowledge is freely shared across participating organizations. Although there are structural similarities among these and the $\mathrm{KB}$, what makes the $\mathrm{KB}$ unique is that the knowledge that is being deposited is not of current interest to the contributing organization; however, it might be of interest to the other organizations or become of interest again to the contributing organization at a later point in time. The $\mathrm{KB}$ is also different from alliances in that alliances require continuous commitment to the partnership and focus only on active research projects.

As presented in Figure 4, the resources are used as inputs to the value- creation process. This is the stage where the knowledge creation takes place by harvesting knowledge and technology from different sponsoring companies, or by further developing the concept into its final form. The results of these efforts are considered to be the output of the KB that will be available to sponsoring companies and other organizations. As a result, the knowledge that had no value to the organization at one point in time is salvaged and improved to become valuable at a later time.

While the KB concept is simple and intuitive, the practical aspects of successfully implementing this concept may be less than trivial. For example, the details of how to capture and deposit the knowledge, how to store it, how to support the process during dormancy, and how to extract the knowledge are not that simple. There are, however, reasonable approaches that may be considered and utilized. These are based on the concepts of minimizing costs, sharing those costs across the broadest set of possible benefactors, and maintaining knowledge-management processes that treat all depositors fairly.

- The prerequisites to become a sponsoring member: In order for an organization to participate in the $\mathrm{KB}$, there needs to be two underlying business processes in place: (1) an idea-tolaunch process such as stage-gate, which enables periodic evaluation and documentation of development projects, and (2) a parallel running knowledge-retention process, which captures knowledge as generated during the development stages. Figure 5 shows this system. When projects are terminated prematurely at the gates, the knowledge generated will be salvaged by transferring it to the $\mathrm{KB}$. The knowledge transferred can consist of prototypes, progress reports, lessonslearned documents, manuals, blueprints, licenses, or patent documents. It is important to deposit all the documentation in a form that will be easy to access and retrieve. The KB should develop standards to guide companies in terms of preparing their documents and reports prior to submission, so that at the $\mathrm{KB}$, data-mining tools are more effective.

- Stakeholders: The main stakeholders are the sponsoring and contributing organizations. These companies gain access to the knowledge and intellectual property (IP) generated at the bank. Over time, new alliances and partnerships can be added to sustain

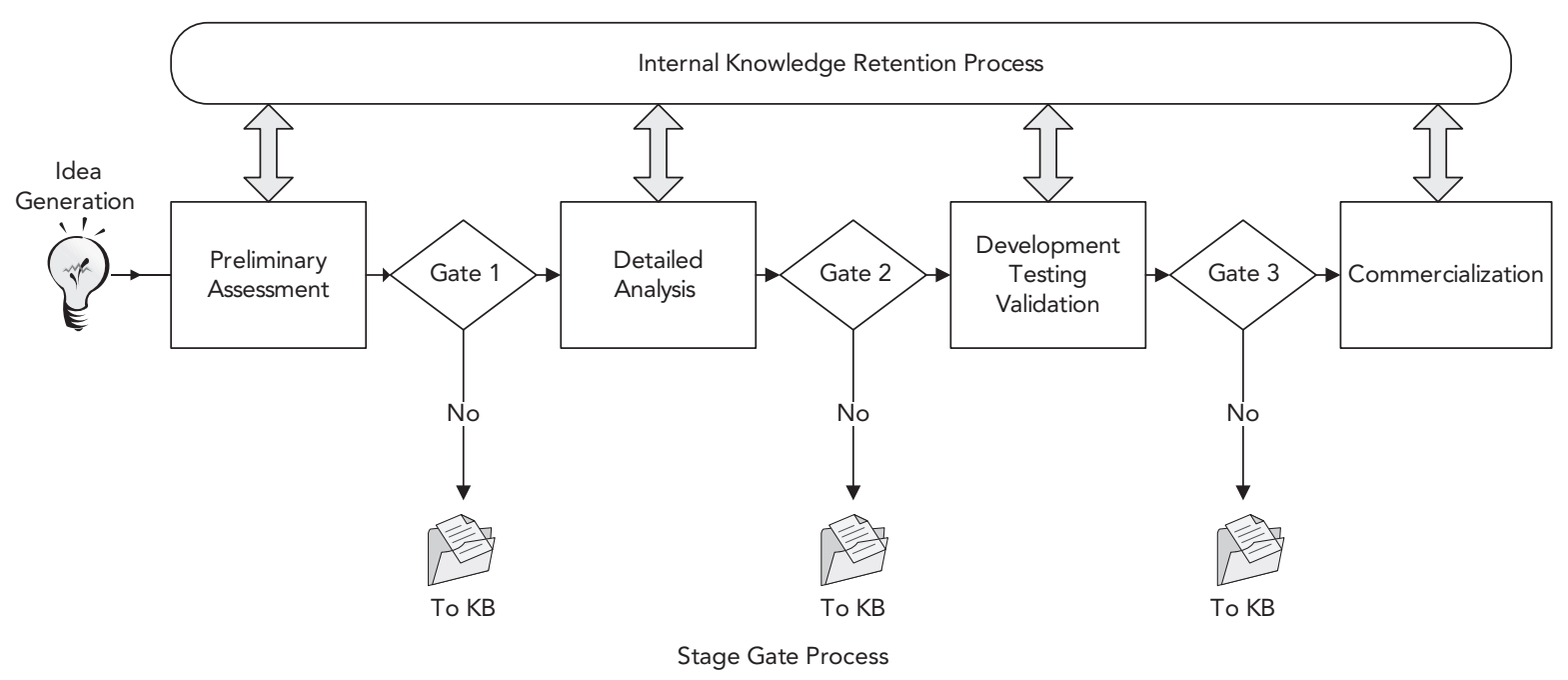

Figure 5: Knowledge-retention process. 
the knowledge base (Alves, Marques, Saur, \& Marques, 2007). The licensing of the IP adds to the pool of stakeholders of the bank and diversifies the background of the stakeholders.

- Knowledge bank office (KBO): The KB needs resources to manage the steady stream of knowledge coming from the sponsoring organizations. The individuals that manage the office could be assigned on a rotating basis from the sponsoring organizations. This office centralizes and coordinates the management of projects as well as controls communications with the sponsoring organizations. One of the critical activities at the office is the identification of the relevance of the knowledge to be deposited to the underlying theme of the bank. The KB can accept the $R \& D$ knowledge base from diverse industries. Thus, another function of the $\mathrm{KB}$ is to facilitate industry convergence for innovation (Broring \& Leker, 2007).

- Intellectual property ownership: Similar to many other collaborative research centers, such as MIT's Media Lab (Haase, 2000), the ownership of IP resides with the $\mathrm{KB}$, although the $\mathrm{KB}$ is committed to license it to the member organizations. The licensing arrangements should be made on a nonexclusive basis, meaning that any member organization can gain access, regardless of the origin of the knowledge. In a recent study, Aoki and Schiff (2008) suggest the creation of IP clearinghouses as a means of promoting accessibility to licenses and patents. KB can assume such a role as well.

- Resources: The employees of the bank should include researchers, scientists, librarians, and an intellectual property specialist. In addition to full-time employees, employees may be assigned on a rotating basis from the sponsoring companies; they could also include students working as interns and faculty from research universities. The employees in general are responsible for adding value to the knowledge made available. Knowledge resources are critical inputs to the value-creation process. The usefulness, completeness, and the readiness of the documentation impact the effort required to store and grow the knowledge. Knowledge-mining tools would be required in this process. Additional resources in the form of laboratory equipment, computer hardware and software, and digital instruments may also be required to investigate the findings provided by the sponsors. The allocation of these different types of resources should be done in an aggregate project planning (APP) framework (Wheelwright \& Clark, 1992). This framework enables the $\mathrm{KB}$ to classify work based on different criteria such as risk, time, and resource needs, and pursue a suitable portfolio of research.

- Funding: After the initial setup of the bank by the members, funding needs to come from the sale or licensing of development work and knowledge. Since most members are unwilling to subsidize the knowledge bank on an annual basis, the $\mathrm{KB}$ would need ongoing sources of income. Unlike the media laboratory, because of the constraints imposed by the intellectual property issues, the $\mathrm{KB}$ is limited in terms of the type of contracts they can pursue.

- Value creation: KB creates a rather comprehensive knowledge resource from the experiences of many organizations. Organizing this knowledge and making it accessible by using datamining techniques or indexing creates considerable value. Once the work is organized in an APP framework, researchers and scientists can also add value in the form of advancing the core knowledge and/or further advancing the commercial development.

- Knowledge retrieval: Periodic seminars, demonstrations, and open houses are all good ways to inform the member organizations about the work being done. Then, when there is renewed interest by the organization regarding a dormant project, it can be resurrected using the KB. Withdrawal of the knowledge can also come in the form of hiring, internships, and rotational assignments by researchers or project employees or possibly through lectures or other negotiated training processes.

- Communication: In order for member organizations to communicate with each other as well as with the $\mathrm{KB}$, a private industrial network can be set up. The network can be Internetbased, and owned and operated by the $\mathrm{KB}$. It can provide a platform for member organizations to share knowledge and closely collaborate. It also enables the fast and accurate deposit of knowledge. In a recent study, Parise and Henderson (2001) indicate that the critical aspect of knowledge exchange between the partners is the position or role of the partner in that industry. A partner can have dual roles, as a competitor and complementor, which might impact the tacitness, specificity, and complexity of the knowledge being transferred. A partner-resource exchange model can be implemented to improve the partnership.

\section{Universities as Knowledge Banks}

There are several possible approaches to capturing and depositing the knowledge into the KB. Institutions that have KM programs are well versed in knowledgecapture practices and could offer these services. Given that this could be a long-term need and relationship, they may have an incentive to subsidize the costs of facilitating the knowledge capture. Depending on the nature of the knowledge and university objectives, the university may be interested in picking up some key employees. From the project's and organization's perspective, they may view this as a form of outsourcing and may be willing to transfer some key employees and perhaps even agree to share salary costs to ensure full transfer. Universities are in the business of managing knowledge and would be the most efficient at it. 
Universities can be unbiased and perhaps perform a pooling function for several organizations that may be in similar positions. Since universities are generally not driven by the desire to make and sell tangible commodities, they may be the one place that several competing organizations can come to, jointly sponsor, and expect a fair return on the invested knowledge.

\section{Simulation of Knowledge and Revenue Growth}

Knowledge, regardless of where it is generated (either at the organizational level or at the knowledge bank), follows an S-curve growth (Christensen, 1992). Given the growth rate of knowledge, the amount of knowledge that accumulates is a function of the current level of knowledge and how far it is from its technological limit. We use the following equation to represent this:

$$
K_{t}=K_{t-1}+g\left(\frac{L-K_{t-1}}{L}\right),
$$

where $g$ is the growth rate, $K_{t}$ is the knowledge level at time $t$, and $L$ is the technological limit. A hypothetical knowledge level being between 1 and 100 , with an aggressive growth rate of 0.2 , Figure 6 represents the knowledge accumulation over a 70 time period at the bank. At around time 40, the knowledge level $K_{t}$ is almost at the technological limit, while a smaller value for $g$ would delay reaching the limit to a later period.

The revenue that an organization can receive during the rapid growth of knowledge should also grow rapidly but should slow down and even may decline as the knowledge reaches its technological limit. Thus, the following equation will be used to develop the revenue graph in Figure 7.

$$
\begin{aligned}
R_{t}= & R_{t-1} * r e v \_g r o w t h \\
& +\max \left(0, K_{t}-\text { mrev }\right) * r e v_{-} \text {increase } \\
& -\max \left(0, K_{t}-\text { marav } * L\right) \\
& * \text { rev_decrease },
\end{aligned}
$$

where $R_{t}$ is the revenue at time $t$ and rev_growth is the percentage of revenue
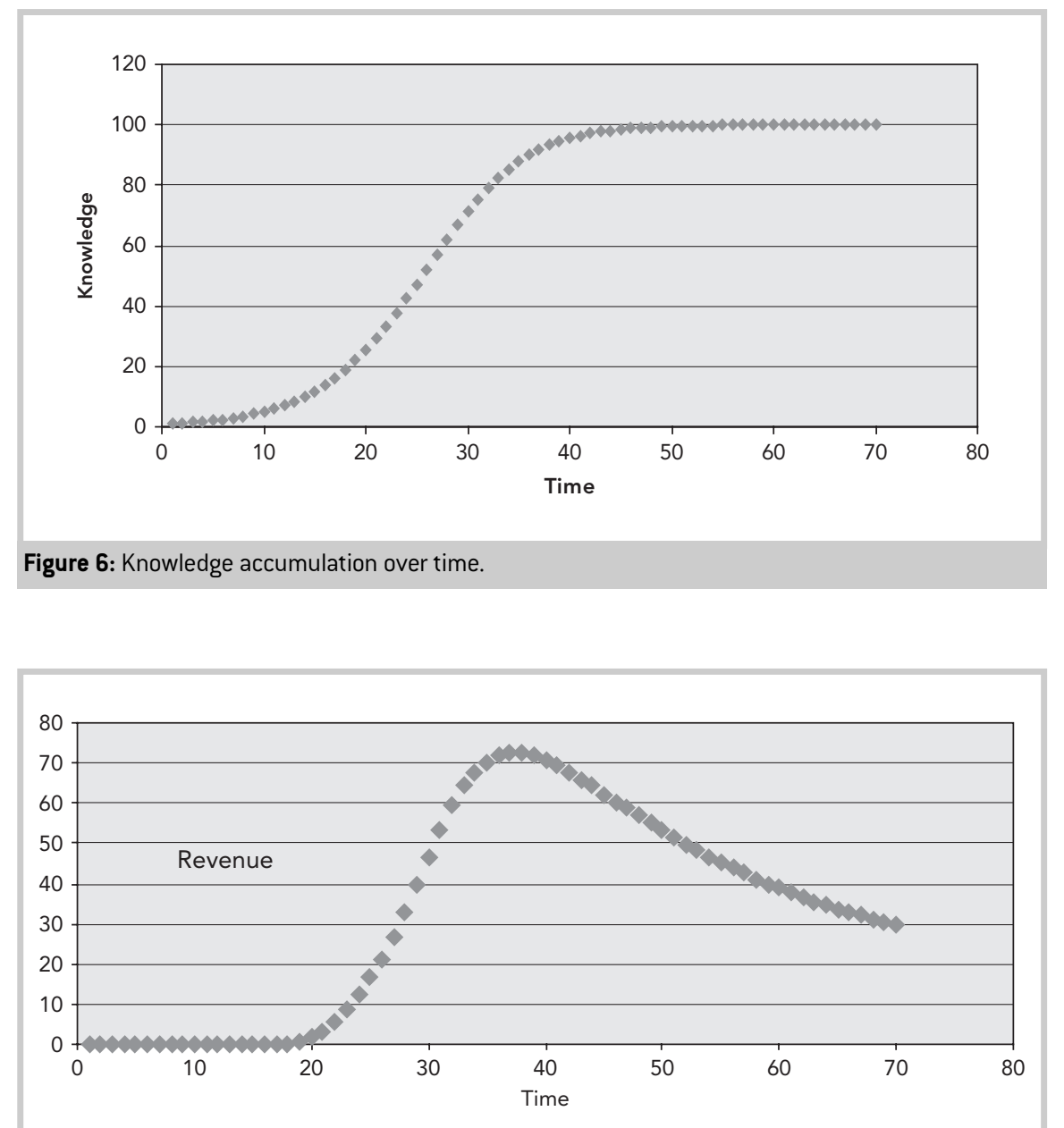

Figure ?: Revenue generation.

carryover from the previous period. When the knowledge level gets beyond mrev, a portion of that (rev_increase) leads to additional revenue, while when knowledge gets closer to its limit, larger than marav, there is a decline in revenue, rev_decrease. The corresponding cumulative profit is given by:

$$
p_{t}=\sum_{i=1}^{t}\left(R_{i}-c_{i}\right),
$$

where $c_{i}$ is the cost incurred in period $i$ and $p_{t}$ is the profit at time $t$. In the equation, we assume that the development cost is linearly related to time. In the revenue figure (Figure 7), we used $R_{1}=0$, rev_growth $=0.95$, mrev $=20$, rev_increase $=0.16$, marav $=0.8$, and $r e v_{-}$decrease $=0.6$, and in the profit figure (Figure 8), we used $c_{i}=50$ for all $i$.

Note that the specific values we used to develop the graphs are chosen arbitrarily, although the functional forms resemble expected patterns. Furthermore, in the simulation study presented in the next section, rather than treating the parameters as constants, we also introduced randomness into the equations. Most organizations have a number of projects that would follow this pattern of evolution, although with different values for the parameters. For the projects that are not pursued by organizations internally, the knowledge bank can be used as an outlet to salvage value out of them. The next section shows how. 


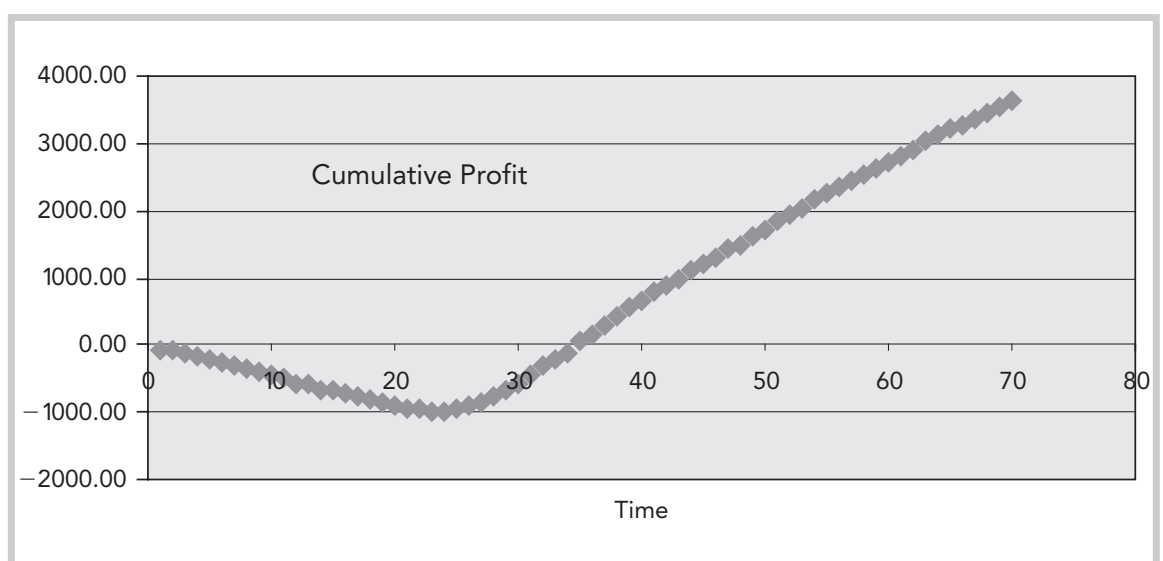

Figure 8: Cumulative profit.

\section{System Dynamics Modeling of KB}

System Dynamics (SD) is a methodology for studying and managing complex feedback systems, such as one finds in business and in other social structures (Sterman, 2000). The suggested KB model possesses interactions and feedback mechanisms between the collaborating organizations and the bank, and thus SD can be used to examine the impact of decisions on the system. As policy decisions are enacted, they can start to change the system itself. Policy decisions must also be revisited at each iteration to access their impact on the system. As a policy decision's impact changes the system, it may no longer be valid and may require adjustment. Figure 9 shows the causal loop diagram for a possible KB.

The diagram consists of two loops that impact the overall model. The first loop is the negative loop that shows cause-and-effect relationships among the $\mathrm{KB}$, resources, and the knowledgecreating firms. As the knowledge bank increases in size, it requires more resources, which has a negative influence on the resources available to transfer the knowledge from the participating firms. The second loop is the positive loop. As the knowledge bank increases in size, there is more development of the knowledge into

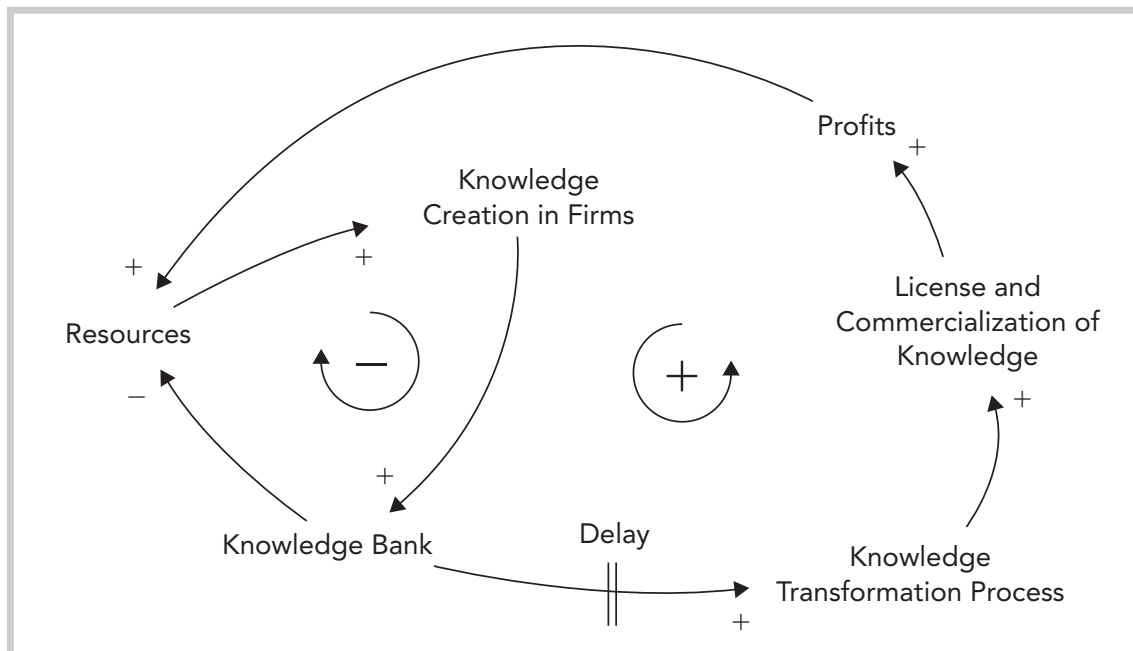

Figure 9: KB causal loop.

licenses, which then generates revenue for the participating firms. The revenue also adds to the available resources. The overall system has a balanced polarity.

\section{The Stock and Flow Map of KB}

Figure 10 is the stock and flow map of the KB system based on the causal loop diagram.

Knowledge flows through the system as follows. The knowledge accumulated from the terminated projects at each firm is submitted to the KB. At KB, the accumulation rate of knowledge follows the graph in Figure 6. Some of this knowledge ages and becomes obsolete, and thus will be removed from the KB stock. On the other hand, some of it will become commercially viable in the form of licenses and will create profits. A portion of the profit will stay in the KB system in the form of resources, while some will be returned to the firms.

\section{Computational Results}

The model described earlier and presented in Figure 10 is simulated using VENSIM. VENSIM is a software application that can be used for developing and analyzing dynamic feedback models. Models can be constructed either graphically or in a text editor. There are a number of modeling applications using VENSIM that can be found in the literature (see, for example, Eberlein \& Peterson, 1992; Garcia, 2006; Morecroft \& Sterman, 1994). We assume that there are three firms and each firm generates knowledge based on a beta distribution. If the knowledge created exceeds a threshold value, the knowledge is available to be transferred to the KB. To transfer knowledge to the $\mathrm{KB}$, resources must be used. The KB has a resource requirement equivalent to the natural log of its size. We further assume that the aging of knowledge results in a $10 \%$ reduction in the bank per year. Knowledge transformation is assumed to take place only when the knowledge accumulation exceeds a threshold value, which is determined by beta distribution. 


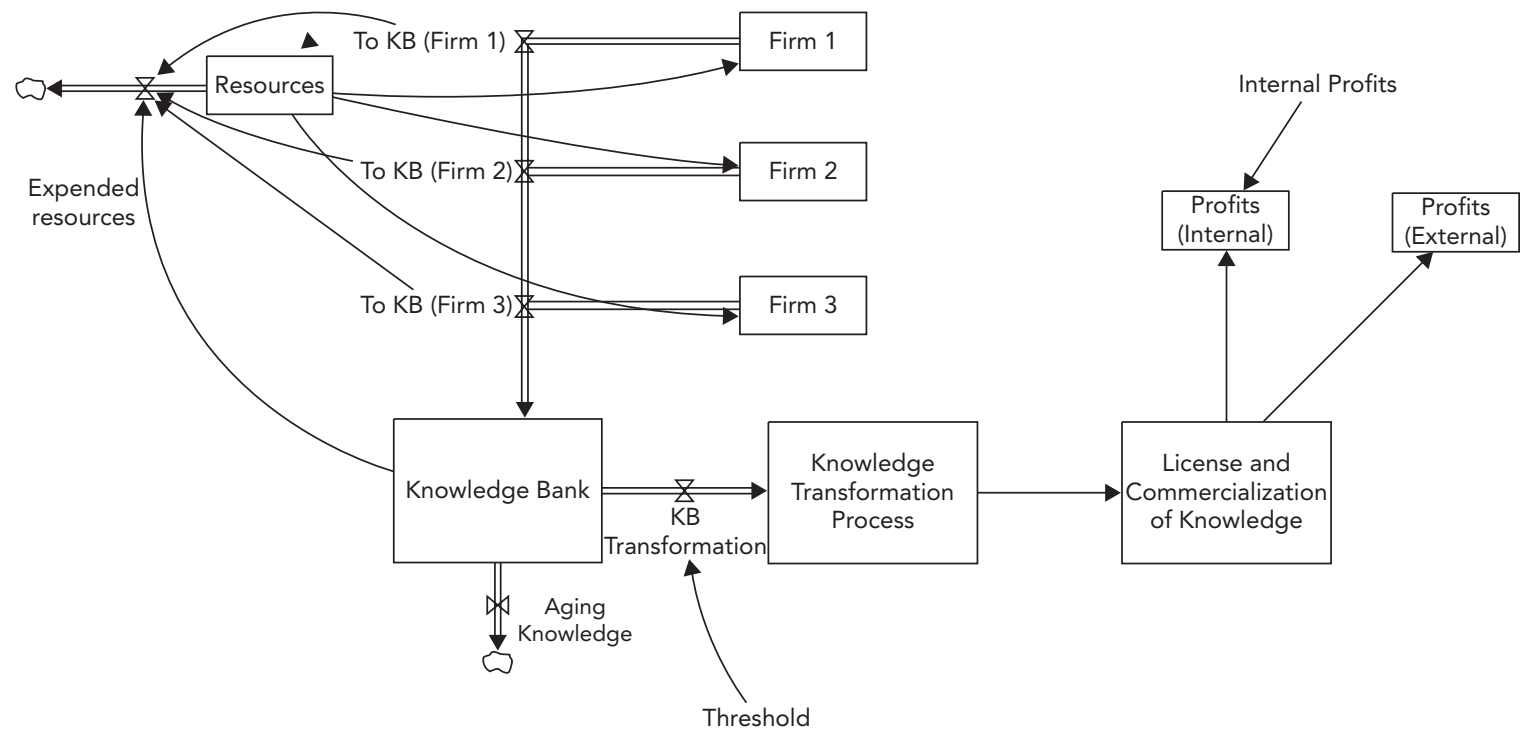

Figure 10: Stock and flow map of KB.

If a successful $\mathrm{KB}$ transformation takes place, there is a four-time period delay before it generates a profit. The profits generated are proportional to the level of the $\mathrm{KB}$ transformation. We assume that $70 \%$ of profit generated is invested back in the KB system, allowing the rest to accrue to the stakeholders. The equations that control the evolution of simulation are given in the Appendix.

Figures 11 to 13 present the results of the study. Figure 11 shows the accumulation rate of knowledge in the bank over a 120 time period. The $y$-axis represents the level of knowledge, with an initial starting value of 100 . Although there is no clear consensus regarding a unit of measurement, some proposed units are lines of code and bytes of data or documentation (Kanevsky \& Housel, 1998). The change in shades in the graphs indicates various confidence levels. Figure 12 shows the resource accumulation in the system, and Figure 13 is the profits generated (in monetary units) for the stakeholders. The $y$-axis in Figure 12 represents the aggregation of resources available (refer to Figure 4) indicated by a common measure such as monetary value. It is important to note that even though we set the system to require $70 \%$ of profits to be invested back in the resources, the KB system can still deliver healthy profits to the stakeholders. This is an encouraging result for consortiums to consider creating a knowledge bank.

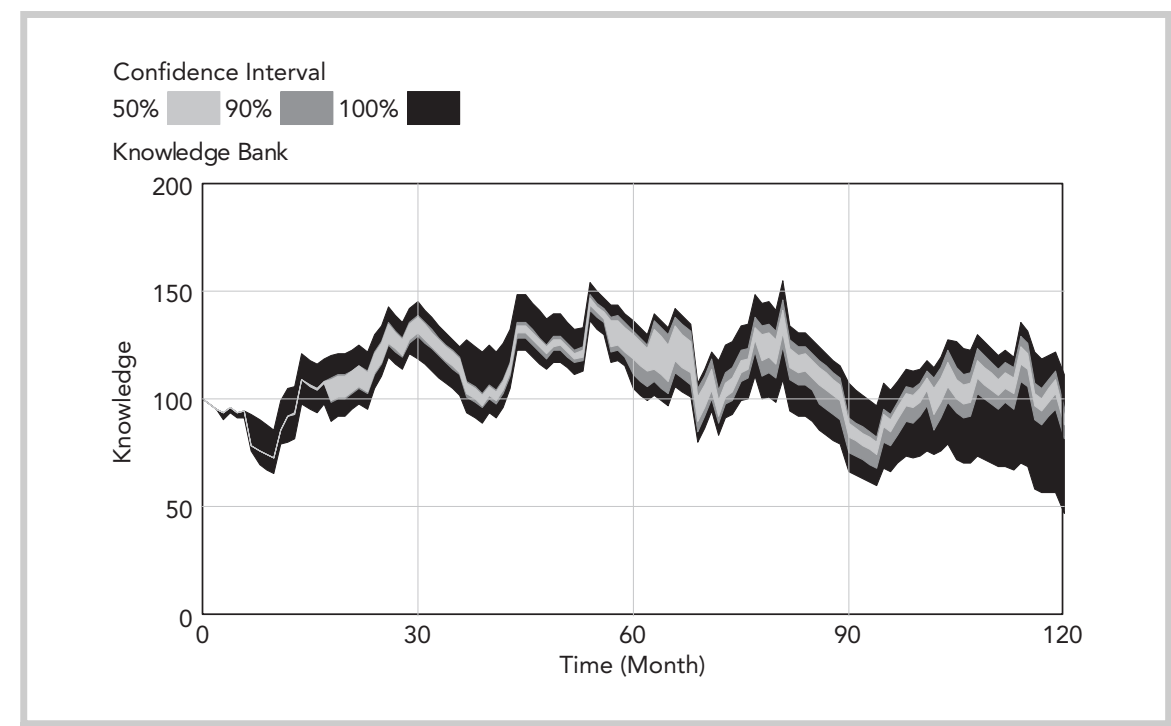

Figure 11: Knowledge level at KB stock. 


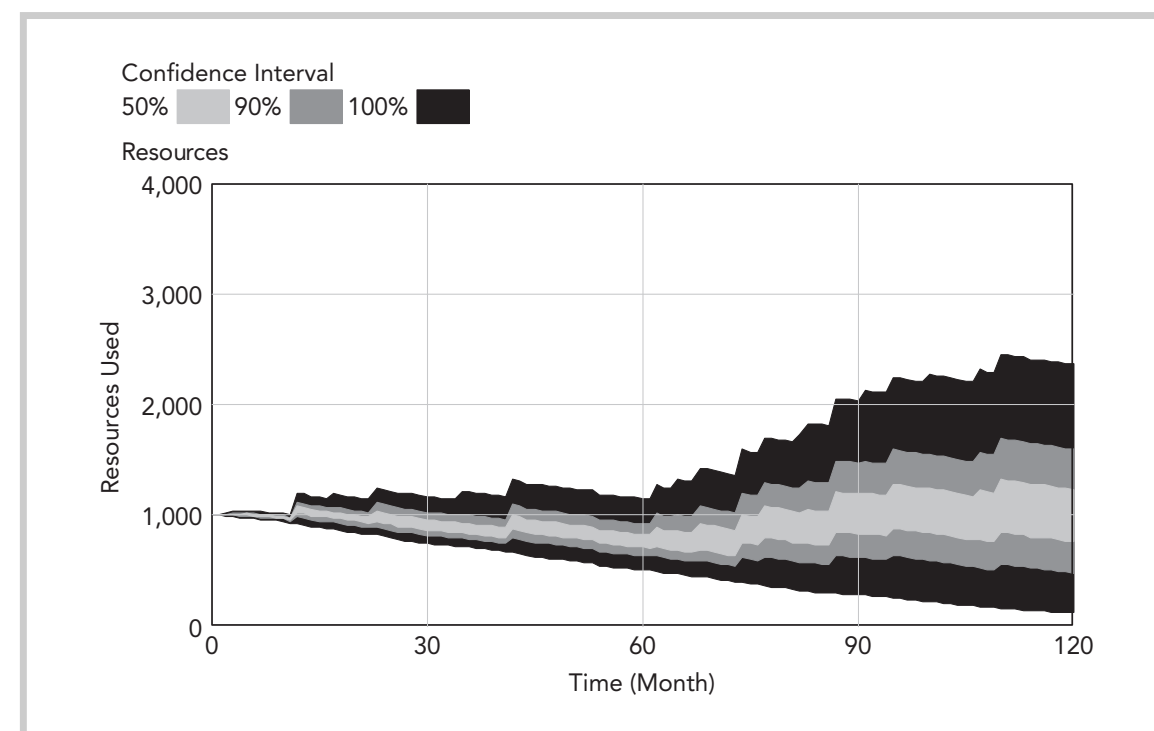

Figure 12: Resource usage in the system.

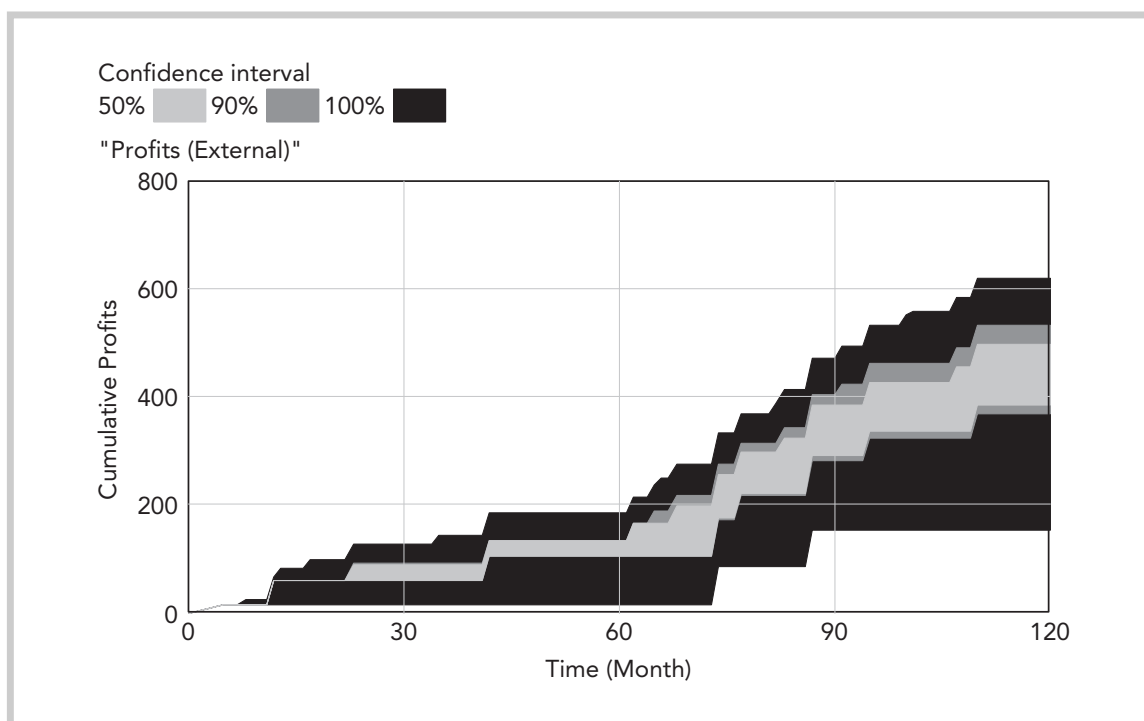

Figure 13: Profit generation.

\section{Conclusions and Future Research}

The formation of alliances and innovation networks to develop, manufacture, and market new products continues to grow (Parise \& Henderson, 2001). Companies form alliances with the intention of accessing capabilities that they lack, to transfer knowledge and technology and expedite the access to markets, among other reasons. IBM's typical alliance is that in alliances, all parties involved have an interest in pursuing the technology, while in the $\mathrm{KB}$ structure, parties do not have interest in pursuing the development of the technology or allocating further resources to that technology. The $\mathrm{KB}$ houses and further develops these unwanted technologies without any consideration to the possible commercialization aspect of it. The KB also differs in the sense that it is an independent clearinghouse of ideas where the contributor and the acquirer of the knowledge need not have any direct contact.

A new knowledge-management concept is presented here that is aimed at addressing the unique needs of dormant projects. The concept, termed knowledge bank, is founded on conceptually simple notions that are based on low-cost, efficient, and perpetual selfsustainment, as well as unbiased knowledge management. These attributes of the knowledge bank offer the project organization the best chance of preserving and possibly even growing the respective knowledge. Rather than having periodic setbacks due to dormancy, the development of the $R \& D$ projects continues, partially due to the KB.

Some questions that invite further research include the determination of how to decide what knowledge to capture and store. Knowing that in the future some form of the knowledge will be needed, how does one go about deciding which knowledge to capture? It is unlikely that many projects will have the ability to collect most of the explicit knowledge and regain access to some of the tacit knowledge as the NASA reactor decommissioning project had. Of course, there is also much more that could be discussed about capturing the identified knowledge, its storage, its growth, and its eventual dissemination.

There are also other possible ways of implementing the knowledge bank concept. Consortia exist today that, in some cases, serve as think tanks, and perhaps these also may want to develop 
a focus on long-term knowledge capture and retention. These may have the advantage of already having a pooled set of resources and interests that may make it easier to transition into a knowledge-broker role.

\section{References}

Alves, J., Marques, J. M., Saur, I., \& Marques, P. (2007). Creativity and innovation through multidisciplinary and multisectoral cooperation. Creativity and Innovation Management, 16, 27-34.

Aoki, R., \& Schiff, A. (2008). Promoting access to intellectual property: Patent pools, copyright collectives, and clearinghouses. R\&D Management, 38, 189-203.

Barney, J. (1991). Firm resources and sustained competitive advantage. Journal of Management Inquiry, 4, 71-90.

Bennett, G. L., Hemler, R. J., \& Schrock, A. (1996). Space nuclear power: An overview. Journal of Propulsion and Power, 12, 901-910.

Bowles, M. D., \& Arrighi, R. S. (2004). NASA's nuclear frontier-The Plum Brook reactor facility. Washington, DC: NASA History Division, Office of External Relations, NASA

Headquarters.

Brand, S. (1988). The media lab: Inventing the future at M.I.T. New York: Penguin.

Broring, S., \& Leker, J. (2007). Industry convergence and its implications for the front end of innovation: A problem of absorptive capacity. Creativity and Innovation Management, 16, 165-175.

Chesbrough, H., \& Crowther, A. K. (2006). Beyond high technology: Early adopters of open innovation in other industries. R\&D Management, 36, 229-236.

Chesbrough, H., Vanhaverbeke, W., \& West, J. (2006). Open innovation: Researching a new paradigm. Oxford, UK: Oxford University Press.

Christensen, C. M. (1992). Exploring the limits of technology $S$-curve, Part
II: Architectural technologies.

Production and Operations

Management, 1, 358-366.

Cooper, R. G. (1985). Selecting winning new product projects: Using the Newprod system. Journal of Product Innovation Management, 2, 34-44.

Day, G. S. (1991). Learning about markets (Marketing Science Institute Report, No. 91-117). Cambridge, MA: Marketing Science Institute.

Eberlein, R. L., \& Peterson, D. W. (1992). Understanding models with VENSIM. European Journal of Operational Research, 59, 216-219.

Elmquist, M., \& Masson, P. L. (2009). The value of a 'failed' $R \& D$ project: An emerging evaluation framework for building innovative capabilities. $R \& D$ Management, 39, 136-152.

Foster, R. (1986). The attacker's advantage. New York: Summit Books.

Garcia, J. M. (2006). Theory and practical exercises of system dynamics. Barcelona, Spain: BPR.

Grant, R. M. (1996, Winter). Toward a knowledge-based theory of the firm. Strategic Management Journal, 17, 109-122.

Haase, K. (2000). Why the media lab works-A personal view. IBM Systems Journal, 39, 419-431.

Hamm, S. (2007). Radical collaboration: Lessons from IBM's innovation factory. Business Week. Retrieved from http://www.businessweek.com/innovate/content/aug2007/id20070830_258 824.htm

Henderson, R. (1988). The failure of established firms in the face of technological change. Unpublished doctoral dissertation, Harvard University, Cambridge, MA.

Huber, G. P. (1991). Organizational learning: The contributing process and the literatures. Organization Science, 2, 88-115.

Kanevsky, V., \& Housel, T. (1998). The learning-knowledge-value cycle. In G. von Krogh, J. Roos, \& D. Kleine (Eds.), Knowing in firms: Understanding, managing, and measuring knowledge (pp. 269-284). London: Sage.

Koskinen, K. U. (2002). Knowledge management to improve project communication and implementation. Project Management Journal, 35, 13-19.

Linton, J. D., \& Walsh, S. T. (2004). Integrating innovation and learning curve theory: An enabler for moving nanotechnologies and other emerging process technologies into production. $R \& D$ Management, 34, 517-525.

Moorman, C., \& Miner, A. S. (1997). The impact of organizational memory on new product performance and creativity. Journal of Marketing Research, 34, 91-106.

Morecroft, J. D., \& Sterman, J. D. (Eds.). (1994). Modeling for learning organizations. Portland, OR: Productivity Press.

Motavalli, J. (2001). Forward drive. San Francisco: Sierra Club Books.

Osawa, Y., \& Yamasaki, Y. (2005). Proposal of industrial research and development performance indices. $R \& D$ Management, 35, 455-461.

Parise, S., \& Henderson, J. C. (2001). Knowledge resources exchange in strategic alliances. IBM Systems Journal, 40, 908-924.

Sahal, D. (1981). Patterns of technological innovation. London: Addison-Wesley.

Spender, J. C. (1996). Making knowledge the basis of a dynamic theory of the firm. Strategic Management Journal, 17, 45-62.

Sterman, J. D. (2000). Business dynamics: Systems thinking and modeling for a complex world. Boston: Irwin McGraw-Hill.

Tukel, O., Rom, W., \& Kremic, T. (2007). Knowledge transfer among projects using a learn-forget model. The Learning Organization, 15, 179-194.

Wernerfelt, B. (1984). A resourcebased view of the firm. Strategic Management Journal, 5, 171-180. 
West, J., \& Gallagher, S. (2006).

Challenges of open innovation:

The paradox of firm investment in

open-source software. $R \& D$

Management, 36, 319-331.

Wheelwright, S. C., \& Clark, K. (1992).

Creating project plans to focus product

development. Harvard Business

Review, 70(2), 70-82. 


\section{APPENDIX}

Based on the stock and flow map of KB in Figure 10, the equations used in the VENSIM study are as follows:

Knowledge transferred from firm $i$ to $\mathrm{KB}$ in period $t$ is:

$$
\text { To } \mathrm{KB}_{i t}=100 \times\left(\frac{\text { Resources }_{t}-150}{\text { Resources }_{t}}\right) \times \max \{\beta(4,2)-0.8,0\},
$$

where the threshold value is set to 150 units.

The resources used in period $t$ are:

$$
\text { Expended resources }{ }_{t}=\sum_{\text {all firms }} \mathrm{To}_{\mathrm{KB}}-\ln \left[\mathrm{KB}_{t}\right]
$$

The level of knowledge left in the bank in period $t$ is:

$$
\mathrm{KB}_{t}=\sum_{\text {all firms }} \mathrm{To}_{\mathrm{K}} \mathrm{KB}_{i t}-\text { Aging Knowledge } \mathrm{t}_{t}-\mathrm{KB} \text { Transformation }{ }_{t}+\mathrm{KB}_{t-1}
$$

The amount of knowledge transformed into a license or other commercialization is:

KB Transformation ${ }_{t}=$ if $\left\{\mathrm{KB}_{t} \times \beta(4,2)-0.8>\right.$ Threshold, $\left.\beta(4,2) \times \mathrm{KB}_{t}, 0\right\}$

where the threshold value is set to 10 . 